\title{
Insights on the nature of language from the study of gesture units
}

\section{Alan Cienki}

Vrije Universiteit, Amsterdam, Netherlands \& Moscow State Linguistic University, Russia

\begin{abstract}
Gesture categories and gesture units are characterized according to both formal and functional criteria. The resultant functional types fall along a continuum according to the degree to which their tokens have conventionalized symbolic status. The more conventional the form/meaning pairing, the more straightforward it is to identify gestures as units. Most types of gesture categories are best viewed as having prototype structures, rather than a category structure with strict boundaries. This view on gesture aligns with some contemporary thinking about linguistic categories, which also espouses a prototype approach. The result is a coherent picture of how gesture interactions with different categories and units of spoken language, taking human audio-visual communication as dynamic and polysemiotic in nature.
\end{abstract}

Key words: gesture, prototype categories, semiotic systems

The tight connections between gesture use and speech production have already been a subject of study for several decades (Kendon, 1980; McNeill, 1985, 1992). On this basis, one might logically expect there to be gestural units that are analogous to linguistic units. To some degree, these expectations are borne out; we can find some formal and functional properties of gestures that parallel comparable properties of spoken language. However, the gestures that people spontaneously produce while talking do not constitute a sign language: they do not follow the kinds of normative standards involved in the production of signs of a sign language. How, then, does gesture, as its own kind of semiotic system, relate to spoken language? What does examining gesture from the point of view of categories and units reveal about its relation to language? We will focus here on manual gestures, given the special and numerous possibilities they afford for articulating forms (Streeck, 2009, ch. 3) and the wide range of their communicative functions (Müller et al., 2014, §VII).

Gestures "go with" talk in different ways, in the sense that they relate to language use on various levels. On a formal level, production of a gesture involves 
a form of motoric articulation. Indeed, one could argue that speech is ultimately gestural articulation that produces sounds which bear the load of providing the major communicative information (Armstrong, Stokoe, \& Wilcox, 1995). But gestures serve a variety of functions that language does as well. Gestures also provide semantic information, via deictic reference (pointing, e.g., Kita, 2003), indexing spatial reference (by showing relative locations), and via representation of entities, relations, and actions (Müller, 1998, 2014). Gestures also serve functions that would traditionally be considered pragmatic in nature, such as qualifying what is uttered verbally, showing the speaker's attitude towards the discourse topic, etc. (Cienki, 2017; Ladewig, 2014b; Bressem \& Müller, 2014). In addition, gestures can relate to the structure of the talk itself, and in this way serve a discourse-structuring function, as in showing distinctions between topics by gesturing in different spaces when talking about them (e.g., Calbris, 2008). Furthermore, gestures can function on the level of interaction between the interlocutors, for example: assisting in managing the turn-taking between them, showing that one is still not done speaking by "holding the floor" with a raised hand. Overall, we find not only that gestures as units align with linguistic units on different levels, but also that gestures relate to linguistic units on multiple levels at once, as gestures are often multifunctional. The relation between categories and units in spoken language and gesture will be explored further below.

Let us turn first to the formal features of gesture units and their production before addressing functional units of gesture. In terms of their forms of production, Kendon (1980) observes that gestures are usually not monadic in form, but consist of a hierarchical structure. As Kendon describes it, a gesture unit can be seen as what the hands and forearms do from when they move from a position of rest until they come back to a rest position. This unit can consist of one or more "phrases", each of which can involve one or more phases. The core of a gesture phrase is the preparation and the stroke, the latter involving the most effortful and dynamic movement. Kendon (2004, p. 111) actually describes gesture as a "movement excursion". Its structure has to do partly with the structure of the arms and hands (Streeck, 2009, ch. 3) and the kinds of movement they afford (Kita, van Gijn, \& van der Hulst, 1998), but also with how the exertion of effort, that they originate from, plays out (Boutet, 2010).

Some main points on gesture production from Kendon $(1980,2004)$ and McNeill (1992) can be summarized as follows. The essence of a gesture is the main stroke produced, which may be preceded by a preparation movement and may be followed by a retraction to a rest position. These three phases (preparation, stroke, retraction) can be seen as the basic building blocks of most gestures. The stroke is the phase with the greatest movement dynamics; it involves the greatest exertion of effort (Laban \& Lawrence, 1947/1974). Here the hand shape and the 
form of the movement have the greatest clarity. In relation to the speech, the stroke phase is usually the portion that relates most closely to the primary function of the gesture; it is through the stroke that the gesture depicts a referent, or performs a pragmatic, interactional, or other function. In these respects, the stroke phase is the essential part of a gesture; it is usually considered the minimum that is needed for constituting what researchers call a gesture. In some cases, a stroke movement is produced with no preparation; this is often the case with pointing gestures, where the hand moves 'in one go' from a rest position into the act of pointing. When there is a preparation phase, the hand is moving from the rest position to get ready to produce the stroke. In this phase, the hand shape for the stroke also begins to appear and develop. After the stroke, there may be a hold, where the hand is held in place where the stroke ended (which can be significant in relation to the production of the speech, as noted below). Following this, there may be another stroke or strokes, after which the hand eventually returns to a rest position, which may or may not be the same as the original rest position.

In relation to these formal features of a gesture unit and its subparts, it is worth considering some features of the production of gestures in relation to units of speech. The burst of effort during which the gestural movement accelerates in the stroke phase often correlates with stressed syllables, at least in languages like English, in which the stressed syllable tends to attract the intonational pitch accent (Gussenhoven, 2015, p. 716). The exertion of effort for the purpose of communication comes out in both channels, yielding parallel or partially overlapping units. This has led Iverson and Thelen (1999) to use the metaphor of conjoined oscillators to characterize how the movement processes of speech and gesture production are related to each other. The metaphor is not intended to portray speech articulation and gestural movement as rigidly tied to each other, but rather to suggest a flexible connection of interdependence. Indeed, there are several ways in which the timing of gesture phrases and the production of the speech whose ideas relate to the gesture strokes may differ. In many cases, as McNeill (1992, p. 25-26) observes, gestures anticipate the co-referential speech. This anticipation could involve milliseconds, or even a few seconds, the latter of which can make for a quite noticeable lag. However, this can easily happen in contexts where the speaker has an image-based concept in mind for expression for which it may take a moment to find the correct words - yet the gestural image can be produced more immediately and precede the speech. Sometimes the speech that is preceded by a co-expressive gesture may be the end of the phrase being uttered. In this case, the post-stroke hold may be held until the speech catches up. In other cases, the final moment of a gesture stroke may be held after the relevant speech has been uttered, such that the hold extends over subsequent speech. Whether the speaker is aware of doing this or not, this can hold the final image 
of the stroke in the air, making it available for some time after the gesture stroke while the speech proceeds to the next idea. This difference in alignment of timing of information being presented in gesture and speech can allow the just-uttered idea to be metonymically kept available for perception (visually), displaying an implied connection to the new idea being spoken. The effects of this very common phenomenon in conversation have yet to be more thoroughly researched.

Kendon (1972) was one of the first to note the remarkable alignment of gesture units with prosodic units in speech. He observed that gesture phrases (preparation + stroke + optional hold) have been found to often align (with varying degrees of precision) with intonation units. An intonation unit can be characterized as "a stretch of speech uttered under a single coherent intonation contour" (Du Bois, Schuetze-Coburn, Cumming, \& Paolino, 1993, p. 47). Interestingly, both intonation units and gesture phrases have been argued to be units that serve to express idea units. Chafe (1994) divides intonation units into substantive and regulatory units. In his research on spontaneous conversations in English and Seneca, he found that while regulatory units serve interactional and discourse structuring functions (among others), each substantive unit adds one new idea unit to the ongoing talk. We can compare this with McNeill's (1992) claim that gestures tend to co-occur with new information being introduced into the discourse. This shared function of substantive intonation units and gesture phrases might be explained by McNeill's $(1992,2013)$ growth point theory of speech and gesture production. Building on proposals from Vygotskij (1934), McNeill proposes that the microgenesis of an idea unit in spontaneous talk involves an unpacking of it into the "linear" sequential structures of the language being spoken in the moment and the more holistic, imagistic aspects, which may appear in the forms and movements of speakers' gestures. The speech and gesture production can mutually influence each other, resulting in what Kendon simply calls the speaker's utterance, which can have audible as well as visible action dedicated to it (Kendon, 2015). Later research has explored gesture as action which aids visual-spatial thinking, regardless of whether the person who is gesturing is speaking. Witness the study by Kita, Alibali, and Chu (2017) on individuals performing mental rotation tasks (having to picture how a geometric figure would look if rotated), who spontaneously gesture to assist in arriving at an answer, even when they are alone and not speaking when doing the task. As a result, Kita et al. (2017) propose what they call the "gesture-forconceptualization hypothesis". Consequently, the debate continues regarding how gesture and speech production are related.

The system described above, of gestures units being comprised of phrases and phases, has been applied extensively in gesture research. However, a widely shared view among those who have done empirical research on gesture produced in natural settings is that sometimes it can be extremely difficult to apply the 
system in practice, in order to formally mark divisions - between a preparation and the stroke phase of a gesture, for example. For some types of research, in which the larger units of "rest position - movement series - rest position" are sufficiently useful, this matter is less of a problem. Witness Leonteva's (in preparation) proposal that lawyers sometimes tie ideas together visually in their opening statements for jury trials by using long gesture units which cover a number of spoken utterances (what she calls narrative gestures). For other types of research, though, in which the sub-parts of the gesture units need to be clearly delineated, drawing the dividing lines between gesture phases can be difficult. Here one can look to the work of phoneticians, who face some similar analytical challenges with speech production as a continuous flow that needs to be parsed for analysis. Kibrik (2012) discusses how situations like this involve not simply discrete structures, like separate objects, and not continuous structures, like the rising pitch that can be played on a trombone, but rather focal structures. A focal structure can be pictured as a tube with some bulges in it (focal points). Many instances of a category may be easier to identify at their focal points than at the edges of the category, where it may be difficult to draw a dividing line. This suggests that, for some types of research, it is not only easier, but also more reliable and more relevant, to identify and code instances according to the focal points, without, or with less, attention to where the dividing lines are between the individual items. In relation to intonation units and gesture phrases, this would mean focussing on the most effortful and conspicuous parts of the gesture phase and of the intonation unit, namely the peak of the gesture stroke and the syllable receiving primary stress. Compare Dahl (1979/1987) on prototype-based categories as having an amoeba-like structure, with the focus being the nucleus in the central portion, and more peripheral exemplars of the category being the leg-like pseudopods extending from the main body of the cell.

The models Kibrik and Dahl present can be applied to various kinds of linguistic categories that function as prototype structures, such as phonemes and morphemes (see Taylor [1989/1995] on linguistic categories on various levels as prototypes). However, it is worth noting that gestures accompanying speech do not comprise a set of "gesturemes": there are not shared, normatively constrained standards for most types of gestures. In connection with this, it is worth considering the continuum along which gestures conventionally have a communicative status. With this, we turn to gestures as playing roles in various functional categories.

Kendon (1988) noted the range along which gestures function as conventional signs, something which McNeill (1992) then characterized along a continuum. At one extreme of the continuum are gestures which are used with or without speech as independent signs in a given linguistic community, like the "thumbs up" gesture to evaluate something positively, or the fist with extended thumb and 
pinkie finger held next to one's ear to indicate calling someone on the phone. Dating back at least to Efron (1941), who calls gestures of this type 'emblems', this category has been recognized as involving fixed pairings of forms with specific meanings, and comprises gestures which people use intentionally to communicate something. At the other extreme on the continuum are gestures which are more idiosyncratic in nature. Examples would be gestures used when depicting various forms, shapes, or actions (see, e.g., Streeck, 2009, ch. 6). The forms produced are not conventionally linked to particular meanings, but are understood with the help of the verbal context in which they are used, and by virtue of iconic relations between the forms of the gestures (through the modes they use to depict [Müller, 1998, 2014]). In between these two extremes of conventionality of pairings of gesture forms and meanings, various other types of gesture categories have been recognized in the literature. Here I will focus on the category identified as 'recurrent gestures' (Bressem \& Müller, 2014). Examples found among German speakers, but prevalent in some other European cultures, include the hand rotating at the wrist (the 'cyclic' gesture [Ladewig, 2014a]) to indicate a process going on, or that one is searching for a word, or that someone should speed up what they are doing; and the raised index finger to indicate that someone should pay attention or that they should wait a moment. Any recurrent gesture can vary somewhat in form (e.g., the cyclic gesture may involve one's arm moving from the elbow, rather than the wrist), but there is a limited range of variations possible, and the set of meanings/functions they serve also involve a limited set. Therefore, recurrent gestures do not involve a one-to-one mapping of form and meaning, but rather a several-to-several mapping, as each side (form and meaning) involves what Wittgenstein (1953) characterized as a family-resemblance category.

In terms of identifying gestures as units, this can be seen as graded along the same scale, described above. This is indicated in Table 1. Whereas emblems are normally clearer in their production, given how they function as independent signs, recurrent gestures are more variable in nature, and consequently, it may be more difficult to identify an instance of use of a recurrent gesture. Finally, at the end of the continuum, more idiosyncratic gestures vary even more greatly in form and in the degree of articulation with which they are produced. They comprise a wide range of possibilities of how they might be produced and for what purposes, meaning that not only may it be variably difficult for researchers to annotate such gestures, but also there may be great variability in the degree to which such gestures are used in conversations as communicative signs (as opposed to just being movements the speaker makes to facilitate his/her own speech production processes). In essence, gestures as a semiotic system show prototype effects (à la Rosch, 1975), in that the category has a range of types of exemplars: from those movements that are more easily identifiably functioning 
as gestures (emblems), to those kinds of movements that form various kinds of sub-categories of gestures (recurrent gestures), to those movements that have a vast range of forms and functions. The latter can include representing entities in vivid depictions, smaller movements that regulate the flow of discourse (perhaps pointing toward the left and then the right while making a complex argument, to parse the discourse), or much smaller 'beats' (back and forth movements) that can add emphasis to certain words.

Table 1. Ease or difficulty in identifying gesture units, depending on gesture type

\begin{tabular}{|c|c|c|}
\hline Gesture type & $\begin{array}{c}\text { Dependence on context } \\
\text { for meaning }\end{array}$ & Identifying units \\
\hline Emblems & little/less & easiest to do \\
\hline Recurrent gestures & more/greater & variably difficult \\
\hline More idiosyncratic gestures & most/greatest & $\begin{array}{c}\text { variably difficult; } \\
\text { sometimes quite difficult }\end{array}$ \\
\hline
\end{tabular}

Ultimately, we see that studying speakers' gestures raises larger questions about talk as a polysemiotic communicative system. It was mentioned above that linguistic categories on various levels have been discussed by some as actually having prototype structures, with clear centers and fuzzy boundaries, rather than being categories with clear and strict boundaries. Rosch (1978) and others analyze word meanings as prototype categories. Jaeger \& Ohala (1984) characterize phoneme categories as gradient, but with salient prototypes. Aarts (2007), Lakoff (1987), and Taylor (1989/1995) all consider grammatical/syntactic constructions as prototype categories. Bybee (2010, p. 2) draws the conclusion that, "All types of units proposed by linguists show gradience, in the sense that there is a lot of variation within the domain of the unit (different types of words, morphemes, syllables) and difficulty in setting the boundaries of the unit". In light of this, gestures as categories (and as a category) can be understood and analyzed in a similar, prototype manner. In other work (Cienki, 2012, 2017), I have proposed language itself might best be recognized as a prototype category. If the center of language as a prototype category is constituted by lexical and grammatical items, then there is a fuzzy boundary where it overlaps with other potentially communicative forms, such as non-lexical vocalizations, like 'um' and 'uh' (Ward, 2006). But language also overlaps with other semiotic modes and codes, such as wordless intonation contours that are vocalized (e.g., to indicate doubt in English with a rising pitch when saying 'huh'), or gestures. The fuzzy boundary of language overlaps with these other semiotic systems in a variable fashion, depending on the context. We might rely more on gestures when trying to communicate through a glass wall, but will 
rely more on linguistic and non-lexical sounds when listening to, but not looking at, someone who is speaking. Spoken language, intonation, gesture, and other means of embodied expression are thus semiotic systems that overlap with each other to varying degrees, and along various time scales (Cienki, 2012, 2015, 2017). This view is coherent with approaches that treat communication as activity in a complex dynamic system (Ellis \& Larsen-Freeman, 2009).

In conclusion, we can say that on one level, gestures as units are based on certain form features, which are essentially movement contours, however, the clarity of gestures as units can vary according to gesture functions. Gesture functions overlap with functions of the accompanying speech in different ways, and gesture units overlap with those of spoken language on various time scales. Prototype theory provides helpful insights for analyzing gesture units, especially in relation to units in spoken language of various kinds. The view espoused here is that of analyzing face-to-face talk in view of the complex scene in which it plays a part, namely that of polysemiotic communication.

\section{References}

Aarts, B. (2007). Syntactic Gradience: The Nature of Grammatical Indeterminacy. Oxford: Oxford University Press.

Armstrong, D. F., Stokoe, W. C., \& Wilcox, S. E. (1995). Gesture and the Nature of Language. Cambridge: Cambridge University Press.

Boutet, D. (2010). Structuration physiologique de la gestuelle: Modèle et tests. Lidil, 42, 77-96.

Bressem, J., \& Müller, C. (2014). A repertoire of German recurrent gestures with pragmatic functions. In C. Müller, A. Cienki, E. Fricke, S. Ladewig, D. McNeill, \& J. Bressem (eds.). Body - Language - Communication: An International Handbook on Multimodality in Human Interaction, (volume 2, pp. 1575-1591). Berlin: De Gruyter Mouton.

Bybee, J. (2010). Language, usage, and cognition. Cambridge: Cambridge University Press

Calbris, G. (2008). From left to right...: Coverbal gestures and their symbolic use of space. In A. Cienki \& C. Müller (eds.), Metaphor and Gesture, (pp. 27-53). Amsterdam: Benjamins.

Chafe, W. (1994). Discourse, Consciousness, and Time. Chicago: University of Chicago Press.

Cienki, A. (2012). Usage events of spoken language and the symbolic units we (may) abstract from them. In J. Badio \& K. Kosecki (eds.), Cognitive Processes in Language, (pp. 149-158). Bern: Peter Lang.

Cienki, A. (2015). Spoken language usage events. Language and Cognition, 7, 499-514.

Cienki, A. (2017). Ten Lectures on Spoken Language and Gesture from the Perspective of Cognitive Linguistics: Issues of Dynamicity and Multimodality. Leiden: Brill.

Dahl, Ö. (1987). Case grammar and prototypes. In R. Dirven \& G. Radden (eds.), Concepts of Case, (pp. 147-161). Tübingen: Gunter Narr. (Originally published in 1979 in The Prague Bulletin of Mathematical Linguistics, 32, 3-23.) 
DuBois, J. W., Schuetz-Coburn, S., Cumming, S., \& Paolino, D. (1993). Outline of discourse transcription. In J. A. Edwards \& M. D. Lampert (eds.), Talking Data, (pp. 45-87). Hillsdale, NJ: Lawrence Erlbaum Associates.

Efron, D. (1972). Gesture, Race and Culture. The Hague: Mouton. (Originally published in 1941 as Gesture and Environment. New York: King's Crown Press.)

Ellis, N. C., \& Larsen-Freeman, D. (eds.) (2009). Language as a Complex Adaptive System. Ann Arbor, MI: Language Learning Research Club.

Gussenhoven, C. (2015). Suprasegmentals. In J. D. Wright (ed.), International Encyclopedia of the Social \& Behavioral Sciences (2nd edition, volume 23, pp. 714-721). Amsterdam: Elsevier.

Iverson, J. M., \& Thelen, E. (1999). Hand, mouth and brain. The dynamic emergence of speech and gesture. Journal of Consciousness Studies, 6(11-12), 19-40.

Jaeger, R. \& Ohala, J. (1984). On the structure of phonetic categories. Proceedings of the tenth Annual Meeting of the Berkeley Linguistics Society, 15-26.

Kendon, A. (1972). Some relationships between body motion and speech. In A. Siegman \& B. Pope (eds.), Studies in Dyadic Communication, (pp. 177-210). New York: Pergamon Press.

Kendon, A. (1980). Gesticulation and speech: Two aspects of the process of utterance. In M. R. Key (ed.), The Relation Between Verbal and Nonverbal Communication, (pp. 207-227). The Hague: Mouton.

Kendon, A. (1988). How gestures can become like words. In F. Poyatos (ed.), Cross-Cultural Perspectives in Nonverbal Communication, (pp. 131-141). New York: C. J. Hogrefe.

Kendon, A. (2004). Gesture. Visible Action as Utterance. Cambridge: Cambridge University Press.

Kendon, A. (2015). Gesture and sign: Utterance uses of visible bodily action. In K. Allen (ed.), The Routledge Handbook of Linguistics, (pp. 33-46). London: Routledge.

Kibrik, A. A. (2012). The challenge of non-discreteness: Focal structure in language. Talk presented at the Societas Linguistica Europaea conference, Stockholm, August 31.

Kita, S. (ed.) (2003). Pointing: Where Language, Culture, and Cognition Meet. Mahwah, NJ: Lawrence Erlbaum.

Kita, S., Alibali, M. W., \& Chu, M. (2017). How do gestures influence thinking and speaking? The gesture-for-conceptualization hypothesis. Psychological Review, 124(3), 245-266.

Kita, S. van Gijn, I. \& van der Hulst, H. (1998). Movement phases in signs and co-speech gestures, and their transcription by human coders. In I. Wachsmuth \& M. Fröhlich (eds.), Gesture and Sign Langauge in Human-computer Interaction, (pp. 23-35). Berlin: Springer.

Laban, R. \& Lawrence, F. C. (1974). Effort: Economy of human movement. London: Macdonald \& Evans. (Originally published 1947.)

Ladewig, S. H. (2014a). The cyclic gesture. In C. Müller, A. Cienki, E. Fricke, S. H. Ladewig, D. McNeill, \& J. Bressem (eds.), Body-Language-Communication: An International Handbook on Multimodality in Human Interaction, (volume 2, pp. 1605-1618). Berlin: De Gruyter Mouton.

Ladewig, S. H. (2014b). Recurrent gestures. In C. Müller, A. Cienki, E. Fricke, S. Ladewig, D. McNeill, \& J. Bressem. (eds.), Body-Language-Communication: An International Handbook on Multimodality in Human Interaction, (volume 2, pp. 1558-1574). Berlin: De Gruyter Mouton.

Lakoff, G. (1987). Women, Fire, and Dangerous Things: What Categories Reveal About the Mind. Chicago: University of Chicago Press.

Leonteva, A. V. (in preparation). Strategies of Prosecution and Defense in Legal Discourse from a Multimodal Perspective. (Unpublished doctoral dissertation). Vrije Universiteit, Amsterdam \& Moscow State Linguistic University, Moscow. 
McNeill, D. (1985). So you think gestures are nonverbal? Psychological Review, 92, 350-371.

McNeill, D. (1992). Hand and Mind: What Gestures Reveal About Thought. Chicago. University of Chicago Press.

McNeill, D. (2013). The growth point hypothesis of language and gesture as a dynamic and integrated system. In Müller, C., Cienki, A., Fricke, E., Ladewig, S., McNeill, D., \& Teßendorf, S. (eds.). Body - Language - Communication: An International Handbook on Multimodality in Human Interaction, (volume 1, pp. 135-155). Berlin: De Gruyter Mouton.

Müller, C. (1998). Iconicity and gesture. In S. Santi, I. Guaïtella, C. Cavé, \& G. Konopczynski (eds.), Oralité Et Gestualité: Communication Multimodale, Interaction, (pp. 321-328). Paris: L'Harmattan.

Müller, C. (2014). Gestural modes of representation as techniques of depiction. In C. Müller, A. Cienki, E. Fricke, S. Ladewig, D. McNeill, \& J. Bressem (eds.), Body - Language - Communication: An International Handbook on Multimodality in Human Interaction, (volume 2, pp. 687-1702). Berlin: De Gruyter Mouton.

Müller, C., Cienki, A., Fricke, E., Ladewig, S., McNeill, D., \& Bressem, J. (eds.) (2014). Body - Language - Communication: An International Handbook on Multimodality in Human Interaction, (volume 2). Berlin: De Gruyter Mouton.

Rosch, E. (1975). Cognitive representations of semantic categories. Journal of Experimental Psychology: General, 104, 192-233.

Rosch, E. (1978). Principles of categorization. In E. Rosch \& B. Lloyd (eds.), Cognition and Categorization, (pp. 27-48). Hillsdale, NJ: Lawrence Erlbaum.

Streeck, J. (2009). Gesturecraft: The Manu-facture of Meaning. Amsterdam: John Benjamins.

Taylor, J. R. (1995). Linguistic Categorization: Prototypes in Linguistic Theory. Oxford: Oxford University Press. (First published 1989).

Vygotskij, L. S. (1934). Myshlenie i Rech' [Thinking and speech]. Moscow-Leningrad: Sozekgiz.

Ward, N. (2006). Non-lexical conversational sounds in American English. Pragmatics and Cognition, 14, 129-182.

Wittgenstein, L. (1953). Philosophical Investigations. Oxford: Basil Blackwell. 